\title{
STRATA OBJECTS BASED ON MALAYSIAN LADM COUNTRY PROFILE VIA WEB 3D VISUALIZATION
}

\author{
Faraliyana Mohd Hanafi ${ }^{* 1}$, Muhammad Imzan Hassan, Alias Abdul Rahman \\ Department of Geoinformation, Faculty of Built Environment and Surveying, Universiti Teknologi Malaysia, Skudai, MALAYSIA. \\ (E-mail: faraliyanahanafi@gmail,com,imzan@utm.my, alias@utm.my)
}

Commission 4, WG 7

KEY WORDS: 3D Cadastre, 3D strata object, web visualization, LADM

\begin{abstract}
Three-dimensional visualization of 3D parcels have been investigated in many viewpoints in order to fulfil the demands of expanding cities and the increasing complexity of building design. In Malaysia, with the growing strata developed area, particularly residential buildings (i.e., apartments), land administration agencies will need to improve their application in sharing and disseminating cadastral data. Hence, web-based solutions have been recognized as an important visualization requirement among end-users. It acts as a distributed information platform that allows 3D data sharing with the minimal architecture of client-server connects by the internet. There are two key topics addressed in this paper, which is the depiction of 3D strata objects on the web and the linkage to their legal data. This paper also describes the implementation of conceptual model of strata object based on Malaysian Land Administration Domain Model (LADM) Country Profile for the representation of spatial and non-spatial data. Tools such as PostgreSQL with PostGIS extension is used for storing data, CesiumJS was used to handle and visualise 3D strata objects in a 3D browser that was customised as a web application. The results demonstrate a viewer of a multi-storey buildings using web visualization to display both physical and legal information of 3D Strata objects based on LADM country profile (Malaysia). This particular paper also attempts to address 3D visualization of spatial and non-spatial data query using a web application, which also suggests further directions for 3D cadastral visualization development.
\end{abstract}

\section{INTRODUCTION}

Land use has becoming so intense, that different types of 'land' use are being positioned under and above each other, pushing the feasibility of the $2 \mathrm{D}$ traditional technique to its limit, especially in major cities. Cadastre is intricately bound to land and act as a crucial instrument in regulating land-man interaction (Chong,2006).

Cadastre defines that the physical object (strata property) must be linked with the legal object (attributes). From the analysis carried out by Vandysheva et al., (2012); Pouliot and Wang, (2014); Hashim, (2019); Aditya et al., (2020) they stated the challenges to link both 3D objects and the legal properties. Biljecki \& Sindram (2017) also stated that the thematic (attribute) aspect is not always given attention, as many of such datasets are lacking in completeness of attributes. In this research, efforts are made in linking both the physical and legal aspects of a strata property.

The issues on connecting the 3D strata object with its legal data stored in a database are considered in developing the prototype. Other researchers are using a single database to store 2D and 3D cadastral parcels and the RRR's related to the parcels. For example, a study made by Cemellini et al., (2018); Visnjevac et al., (2019); Hashim, (2018) are using a single database such as PostgreSQL and MongoDB to store data. The prototype will require an additional database to store the attribute data. The data retrieval with the visualization of the $2 \mathrm{D}$ and $3 \mathrm{D}$ cadastre objects together with the spatial and non-spatial information so that the visualization and querying of the $3 \mathrm{D}$ situation are possible.
A 3D visualization system to depict rights, restrictions, and responsibilities (RRR) is necessary due to the relevance of 3D information in land and property management including strata properties. Indeed, a national infrastructure for handling land information by governments at all levels is essential, which include national, state and territory, and municipal (Shojaei, 2012).

Hence, this paper aims to design and develop a 3D Strata Visualization via a web environment based on the Malaysian LADM country profile. The objectives are to identify the current tools needed in designing a 3D viewer used in visualizing both $2 \mathrm{D}$ and $3 \mathrm{D}$ platform and to develop a prototype of a 3D web application with linked attributes for 3D strata (multi-level apartment) purposes. The key aspects of this paper are the spatial and non-spatial component of the 3D strata objects are structured based on Land Administration Domain Model (LADM). The main focus will be on the above-ground depiction of 3D strata parcels, as well as the connection between the 3D Strata Viewer and the database to keep the legal information for $3 \mathrm{D}$ parcels. Other challenges regarding on the 3D models such as topology, overlapping, intersection, and etc, efficient data storage, web viewer performance, speed is out of scope. In order to achieve the goal, several questions need to be answered which are:

1. What is the current status and state-of-the-art in 3D cadastral visualization?

2. To what extent does the current practise is being utilized?

3. What is the requirement needed in visualizing 3D strata objects on the web environment?

4. What are the best visualization tools for the 3D strata objects within web environment? 
5. What is the information required in $3 \mathrm{D}$ strata database?

6. How to integrate both physical and legal component of strata objects in a data model and how to practise?

This paper is organized as follows: an introduction on cadastre, and issues related. Section 2 discusses on land administration including 3D cadastre, strata application and requirements, LADM, and cadastral visualization. Section 3 on development of the 3D Strata viewer, while Section 4 explains about user management and discussion and finally, a conclusion.

\section{PREVIOUS WORK ON LAND ADMINISTRATION}

Land administration referred to the process of documenting and disseminating information on everything related to land and its associated resources (Mattsson \& Mansberger, 2017). This section will explain about related literature on land administration, which is cadastre and strata (as cadastral object), also an introduction of the international standard of LADM.

\subsection{D Cadastre}

Cadastre is constantly evolving in response to changing manland interaction act as a crucial tool in administering the relationship between man and land (Chong, 2006). It works as the engine of land administrations system, which aids in the management of land and resource interest. The importance of portraying cadastral information in 3D have been recognized by researchers worldwide in the last 20 years. The representation and visualization of a real 3D world, or as it called 3D Cadastre would provide spatial information related to RRR, not only in 2D land parcels but also 3D space for 3D properties, such as vertical buildings and underground structure (Aien et al., 2012). In Victoria, Australia have begun their Digital Cadastre Modernization (DCM) project by implementing a digital twin in order to upgrade all cadastral information from paper-based plan to digital format (Shojaei et al.,2018). According to Victoria State Government, digital twins Victoria organise and visualize masses of data in one virtual place to create a $3 \mathrm{D}$, digital version of the world which will bring together rich 3D and 4D spatial data, artificial intelligence (AI) and sensor data from across the state. Currently, all 2D plans under Subdivision Act 1988 are supported in the ePlan format, however, strata plan (building subdivisions) is still not supported at this time (Olfat et al.,2020).

A 3D cadastre should be able to store, manipulate, query, analyse, and visualize 3D land rights, restrictions, and responsibilities. However, one of the most crucial aspects of a 3D cadastre is data modelling which will be elaborated further in Section 2.3. The 3D cadastre data model helps users identify the systems structure and behaviour, as well as offering a template in order to allow us as a user to build and implement the $3 \mathrm{D}$ cadastre.

\subsection{Strata Application}

Owing to population growth in Malaysia, there have been substantial stratified underground and aboveground developments in urban areas (Rajabifard et al.,2021). Strata property refers to a scheme where the building or land is carved out into different parcels that include high rises such as flats, apartments, condominiums, and townhouses (Bhatt, 2020). All strata development schemes throughout Peninsular Malaysia and Federal Territory of Labuan are controlled under one legislation namely the Strata Management Act 2013 (Act 757).
This includes condominiums, apartments, flats, shop houses, town house, and landed strata. Figure 1 shows the examples of cadastral object related to strata which include parcel unit, accessory unit, and common property unit. These are basic terminology used in the management of strata. Parcel unit is an individual cubic entity formed by the walls, ceilings, and floor, comprised in a sub-divided building held under separate strata title. Besides that, there is also common property which is the partition of building that are not part of the individual parcel issued by the management corporation. However, an accessory unit is any parcel identified in a Certified Plan (CP) that is utilised in conjunction with a parcel that is used only by the owner or buyer of the parcel unit.



Figure 1. Strata related cadastral object

2D sketches are widely used to construct property documents such as floor plans, cross-sections, and isometric diagrams. Despite the fact that these plans are a common procedure for practitioners', laypeople find it difficult to grasp and perceive this type of drawing (Shojaei et al., 2012). With the representation of strata data in $3 \mathrm{D}$ visualization helps provide solutions as it depicted realistic image that allows easier interpretation and improves decision making.

\subsubsection{Requirement of Strata}

Cadastral parcels are 2D to 3D collections of spaces located all around the world, and parcel representations are defined at various levels of complexities. There are several 3D objects categorized by Kalogianni et al. (2020) which refers to underground or above-ground properties, or the land/water surface. 3D strata object which also consider as 3D objects have basically the similar requirement as other cadastral object. It is as listed below:

a) Examine the strata property units in the context of surrounding 3D environment.

b) To locate a specific 3D strata property unit.

c) To distinguish the boundaries of 3D strata property units and the associated building parts

d) To identify and understand the 3D legal boundary of the strata property units

e) Find adjacent objects of a 3D legal object, both vertically and horizontally to identify affected Right, Restriction and Responsibility (RRR).

f) To distinguish the private and common property 
in strata development.

g) Identify units that are to be merged or subdivided.

h) Visually check the spatial validity and data quality, e.g., volume is closed, no overlap between neighbouring volumes, and no unwanted 3D gaps.

i) Perform 3D measurements such as such as calculating the surface area or volume of the strata property.

j) Support other management system such as land taxation, urban planning, registration and many more.

\subsection{Land Administration Domain Model (LADM)}

The LADM is a conceptual model and one of the first spatial domain standards within ISO TC211, with the goal of providing an extensible foundation for efficient and effective Land Administration System development based on a Model Driven Architecture (MDA) and allowing involved parties to communicate based on the shared ontology implied by the model (Kalogianni et al., 2020). This standard is related to four packages which is parties (people and organizations), basic administrative units, rights, responsibilities and restrictions (ownership rights), then, a spatial unit (parcels, and the legal space of buildings and utility networks), also spatial sources (surveying) and spatial representations (geometry and topology) (ISO, 2012).

Multiple country profiles have been developed including Malaysia, as well as several LADM implementations through technical models and encodings. Furthermore, with the growing demand for 3D land administration data, LADM has been widely used around the world since it allows the 3D representations of spatial unit representations without burdening the existing 2D representations (Kalogianni et al., 2020).

\subsubsection{Malaysian LADM Country Profile (Strata Objects)}

The international Land Administration Domain Model (LADM) standard has established a structured conceptual model for cadastral data recording and management (Rajabifard et al., 2019). It includes both spatial and administrative elements, as well as standardized class name for each of them. In Malaysia, Zulkifli et al., 2014 have proposed a country profile (data model) for 2D and 3D cadastral registration based on LADM specifications. It consists of two parts: spatial and administrative. Based on ISO 19152, LADM describes a 3D parcel as a spatial unit against which the entire entity is aligned with (one or more) special and homogeneous rights (e.g. ownership right or land use right), obligations, or constraints. In the case of strata objects representation, it has parcel, accessory parcel, common property, limited common property, and land parcel (Zulkiflie et al., 2019). The Strata Titles Act 1985 (Act 318) and the Strata Management Act 2013 (Act 757) are crucial for most of the land administration in Malaysia, and this is particularly true in many 3D-related situations. Hence, this paper attempts to visualize 3D strata objects using a web-based platform based on LADM Country Profile.

\subsection{Cadastral Visualization}

The display of ownership borders and related descriptive data of measurements such as (length, azimuth, area and ownership) on 2D maps or legal documents such as title, deed or mortgage is referred to as cadastral visualization. Adding an interactive 3D visualization system with a third geometric dimension allows users to explore the intricacies and depth of a 3D situation while overcoming the issues on the traditional 2D technique (Pouliot et al., 2018). The visualization of cadastral parcels poses a hurdle since it will require to display both information about the physical and legal aspects.

3D applications have traditionally relied on high-end computers and commercial software such as ArcGIS Pro, Revit, SketchUp Pro, and many more. The usage of a desktop programme has proven to be useful tool for recording, storing, analysing, and disseminating land data. Today, the internet, which serves as an online platform, aids in enhancing interoperability when it comes to sharing and accessing 3D Cadastre data and issues.

Displaying a spatial data in a web browser, allows for easier data sharing across various types of users. To conduct spatial data visualization, most developers have adapted a number of programming languages, libraries, and frameworks. When it comes to 3D models, researchers have developed different type of data standards such as CityGML, that allow data to be shared between software applications as well as over the web (Rees, 2019).

\section{DEVELOPMENT OF 3D STRATA VIEWER}

The section provides an overview of the data preparation process that describes the architecture, designation of the web, and the database development.

\subsection{Data preparation}

This sub-section explains the 3D modelling and data conversion process.

\subsubsection{D strata modelling}

SketchUp is a 3D modelling software that can be used to design, document and communicate ideas in $3 \mathrm{D}$ with various features to support user's requirements. The 3D strata object was drawn using SketchUp Pro 2019 as shown in Figure 2 based on the measurement given in the floor plan. To be able to export data one by one, the strata unit and common property were set in separate layers. Based on the developed strata objects model, block is referring to MY_Building class, parcel refer MY_ParcelUnit class, accessory refer to MY_AccessoryUnit class, common area refers to MY_CommonPropertyUnit class and land parcel refer to MY_LandParcel class.

Starting from the ground floor, the height of each floor extruded three meters each. In the meantime, it is important to ensured that the layering is right, to prevent any issues happen in future. To enhance the appearance of the building and make it more realistic, additional features such as doors, windows and balconies were introduced using the software's 3D warehouse. However, the layers of each item from the warehouse have been defined by the creator of the object, hence, make sure to adjust it according to its data layer. 


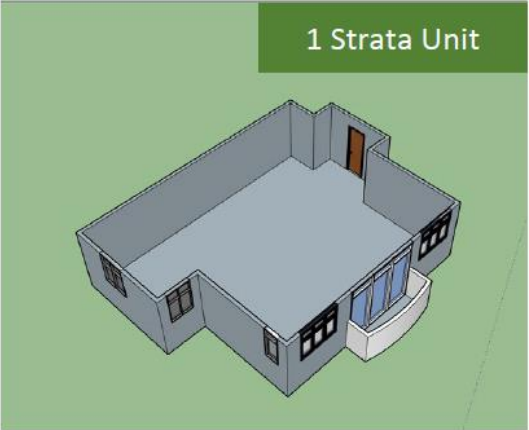

Figure 2. 3D model of a strata unit

SketchUp Pro provide built-in features to add location which effectively applies latitude and longitude coordinates in order to simulate where the data would be located. Figure 3 below shows the model after it has been geolocated using DigitalGlobe provider.

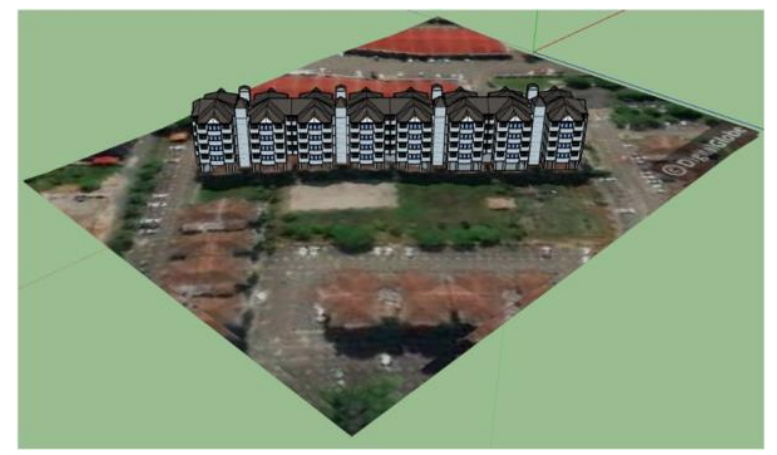

Figure 3. shows the result of 3D model using SketchUp Pro 2019

\subsubsection{Data Conversion}

FME provide a built-in support to simply read and write data in order to convert it from one format to another. From SketchUp, the data was exported to KMZ file. Since the model is georeferenced, it carries geographic coordinate system (WGS 84) and can be viewed via Google Earth. The data can be translated to Cesium 3D tiles once the model has been successfully viewed on Google Earth. To do this, transformers called Geometry Filter were added to the workflow as shown in Figure 4. Geometry filter was used to routes a feature based on its geometry type which in this case is a 'surface'. Each feature that enters the transformer is output via the port corresponding to its type. Each output feature has a complete, unaltered copy of the source feature's attributes and geometry. It's a 1:1 data conversion which means Cesium can read each unit individually.



Figure 4. The workflow of data conversion

\subsubsection{D PDF Generation}

3D PDF (Portable Document Format) is a PDF file embedded with geometry inside. The universal PDF format is often used for documentation, sharing, and collaboration within clients and remote members. Just like a PDF containing an embedded image, except that the user may rotate, zoom, pan, and explore the scene within $3 \mathrm{D}$ view. The file contains a 3D geometric representation of the scene and not just images from different viewpoints. But not all PDF viewers support 3D. The PDF itself is ISO32000, a published ISO standard used by many vendors and industries. It is a container, wrapper within a document of several kinds of content, most often text and images. It can also contain rich media, interactive content, including full 3D viewports (PDF3D, 2018). The built-in 3D features can be used for geospatial and engineering applications where analysis and measurement are within a PDF document, eliminating the need to run specific GIS software (PDF3D, 2020). High-quality 3D content created in professional 3D CAD or 3D modeling programs and incorporated into PDFs can be viewed and interacted with within Acrobat. A 3D model initially appears as a two-dimensional preview image. 3D toolbar view controls and $3 \mathrm{D}$ navigation tools allow the viewer to manipulate the 3D model by clicking it with the Hand or Select tool enables (or activates) the model (Adobe Acrobat, 2020).

Specialized software applications such as 3D PDF Pro, Tetra4D converter, 3D Analyzer, ProgeCAD, etc offer tool sets for template design, 3D data conversion and script embedment in one package. This allows user to easily produce 3D PDF's from initial CAD geometry without having to worry about the technical details.

Furthermore, based on the previous work done by Shojaei et al., (2013), the implementation 3D PDF data format for their 3D cadastral prototype system. Google SketchUp and Simlab Soft plugin are used for 3D PDF file-based generation using survey plan. Besides that, it also provides cross-sections views for visualizing the inner complexity of buildings. Cross-sections are views revealed by slicing an object at a plane. The plane is often but not necessarily vertical. The resulting cutaway view facilitates an understanding of the inner complexity and details of buildings. A method proposed by Oberwinter \& Kovacic, (2012) of using Adobe's 3D PDF engine along with embedded, JavaScript based interfaces has also been done to easily 
accessed and handle Building Information Model (BIM) by enhancing the basic 3D PDF functionality through customizable, JavaScript based features.

Thus, the process of 3D PDF creation consists of several phases which relies on several software packages as shown in Table 1. All these steps are necessary to create the final document, but once it is finished the user only needs Adobe Reader (version 10 or higher) to open and manipulate it.

\begin{tabular}{|l|l|l|}
\hline Process & Software & Exported file format \\
\hline 3D model & SketchUp 2019 & OBJ \\
\hline Read OBJ file & Adobe Photoshop CC 2018 & 3D PDF \\
\hline Viewing the final document & Adobe Reader Pro DC & 3D PDF \\
\hline
\end{tabular}

Table 1. The process involved in 3D PDF Generation

\subsection{Web Design}

This section provides an overview on the development of 3D Strata Viewer which include the architecture design, user interface and platform used, CesiumJS.

\subsubsection{Web Architecture Design}

The architecture is divided into three tiers, as shown in Figure 5: data tier, application tier, and client tier. The 3D models, a PDF file, and administrative data are included in the data tier. Furthermore, the application tier is responsible for publishing the $3 \mathrm{D}$ cadastral data in this prototype using Apache while the client tier visualizes the $3 \mathrm{D}$ models derived from the data tier using a Graphical User Interface (GUI). The GUI was created using a variety of technologies including CesiumJS, HTML, CSS and JavaScript.



Figure 5. The proposed architecture for design and development of the prototype

\subsubsection{Graphics User Interface (GUI)}

The user interface of the 3D Strata viewer is divided into several section: main section, textual data section, control section and 3D PDF viewer section.

The main section is the map canvas section where all 3D cadastral data are visualized located on Cesium platform. With interactive layout, user can rotate, pan, zoom, and click the content which activates the textual data section on the selected item.

The control section of the user interface provides different option of controlling the application and querying data. By using options in the control section, it is possible to perform simple query data name, parcel id, and etc. Lastly, 3D PDF section, which is to enable data sharing and provide additional views towards strata buildings such as cross sections view shown in Figure 6, wireframe view, and vertices. It also provides additional functions such as lighting adjustment and 3D measurement tool.

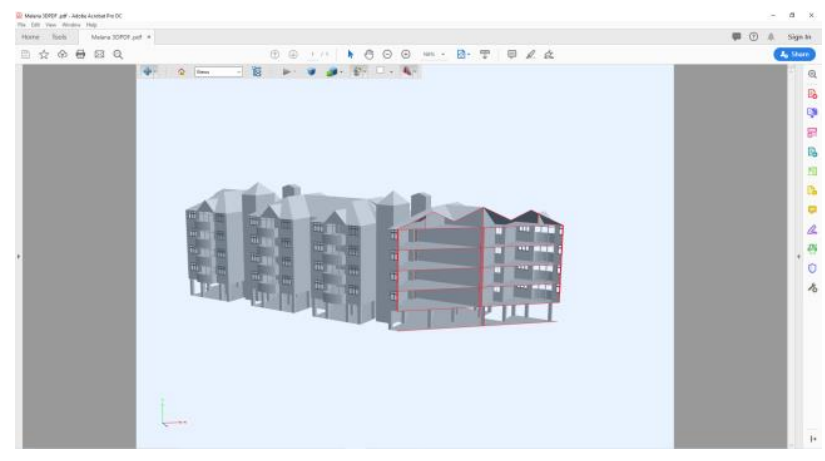

Figure 6. The cross-section view in $3 \mathrm{D}$ PDF

In order to define what is the best way to visualize $3 \mathrm{D}$ cadastral data. It is important to analyse the existing literature and define a list of requirements. Listed below are common function used in a Graphic User Interface (GUI) of a 3D web viewer available currently.

a) Identify tool - To gain information attached to each strata parcel.

b) 3D measurement tool - To measure distance of the $3 \mathrm{D}$ model.

c) Cross-section tool - To display the interior geometry of a structure.

d) Various views - The viewer should be efficiently designed in the prototype to display and interact with $3 \mathrm{D}$ objects for better navigation. In order to give the user, the most natural type of control over the object, the camera should always face the top of the screen.

e) Search and find tool - The ability to query, to find and classify strata objects.

f) Move, undo tool - It is necessary to move an object in some cases i.e., parcel lot from its original position for detailed viewing individually. A tool like this enables any highlighted object in the view to be shifted back to somewhere else A simple undo button will shift the object back to its previous position.

g) Object control - Provide users with control over object visibility that enables viewing of any variation of physical and legal objects.

h) Representing Administrative Information - an option to view administrative information.

\subsubsection{CesiumJS}

CesiumJS is an open-source JavaScript library built on the Web Graphics Library (WebGL) for interactive visualization of 3D globes and 2D maps in a web browser. It helps provides 3D data visualization without the use of plugin. Cesium supports variety of data, and according to Mete et al., 2018, it is possible to visualize point clouds, photogrammetry models, CAD/BIM models, KML data, COLLADA, CityGML, OpenStreetMap, and shapefiles data. 
Furthermore, Cesium has the ability to merge 2D and 3D geospatial data into a single platform for display and analysis, making it an ideal option to be used as a 3D cadastre platform (Aditya et al.,2020). Cesium also has developed a format called $3 \mathrm{D}$ tiles which is an open format as it allows streaming data efficiently and optimized for rendering. So Cesium ion for use in a Cesium JS application, allows people to discover other 3D content and govern their assets using tokens, which allows retrieval of data, and utilize it using Cesium JS, to render, to style, analyse and interact with it. Next section will be explained on the LADM data model implementation on database development.

\subsection{Database development based on LADM}

The development of the database is designed based on the Malaysian LADM Country profile and implemented using PostgreSQL. PostgreSQL is an object-relational database management system (ORDBMS) with an emphasis on extensibility and standards compliance. PostgreSQL has updatable views and materialized views, triggers, foreign keys, support functions and stored procedures, and other expandability (Rajabifard et al., 2021). Next section will be discussed on the spatial and non-spatial component related to 3D strata objects based on LADM.

\subsubsection{Spatial Component}

In the model, one strata object type remains to be represented in 2D, MY_LandParcel (with building no more than 4 storeys). The other strata objects are all proposed to be in 3D as shown in Appendix A (blue classes) and therefore inherit form an abstract class (MY_Shared3DInfo) with strata specializations (and mutual aggregation relationship) called as MY_BuildingUnit, MY_ParcelUnit,

MY_CommonPropertyUnit,

MY_AccessoryUnit,

MY_LimitedCommonPropertyUnit.

Malaysian country profile has indicated several abstract classes that is: MY_SpatialUnit, MY_Shared3DInfo, MY_GenericLot. These classes are used only to support the modelling process, to represent shared attributes and will not get any instances (and therefore no corresponding table in database implementation)

\subsubsection{Non-spatial component}

The non-spatial component consists of object classes that are used to represent the legal aspect of LADM. It consists of the Party and Administrative packages as shown in Appendix B. In party packages, the main class is called as MY_Party, MY_GroupParty represent any number of parties forming together as an entity and Party member.

The packages are associated to each other to show the relationship of ownership with their rights. The administrative packages related to an abstract class of MY_RRR with three main subclasses called MY_Right, MY_Restriction, and MY_Responsibility. A subclass of MY_Mortgage is inherited by MY_Restriction associated to MY_Rights such as transfer, lease, charge, easement, caveat and others. It may be associated with zero or more rights.

A BAUnit represent the basic administrative unit as a subject registration (by law) consisting of zero or more spatial unit with a unique (held by one or more parties) and homogeneous rights, restrictions and responsibilities as included in the land administration system (ISO, 2012). A BAUnit has a unique identifier when registered or recorded but it can consist zero spatial unit, when the registry exists but not a cadastre. Hence, the MY_BAUnit classes are used to register the basic property units, that consist of several spatial units belong to a party under the same rights.

The most important element in administrative package is called MY_AdministrativeSource as it holds the document as evidence showing the rightful owner. It is also used to describe and transaction (deed) or a judgement of register holder. MY_AdministrativeSource are associates with MY_RRR and MY_BAUnit. In Malaysian LADM country profile, identifier for the administrative source is the title number. However, there are additional classes added in the administrative part of the data model which called as MY_Developer class which is crucial for strata management. The developers are responsible in managing and maintaining the buildings as well as controlling legal fund, insurance and many more.

\section{3D STRATA VIEWER: PROTOTYPING 3D VISUALIZATION}

\subsection{User Management}

In the development of the 3D Strata Viewer, users are a crucial factor to consider since they are the ones who will be operating on the application. There are three types of users categorized by registered user, administrators and super administrators. Registered users are those who own a strata unit, administrators are those who work in land offices, and super administrators are those who has the ability to update, and maintaining the data. Users must have a clear understanding of the features accessible to them in order to perform their role in the system. Table 2 below shows the features available for each user.

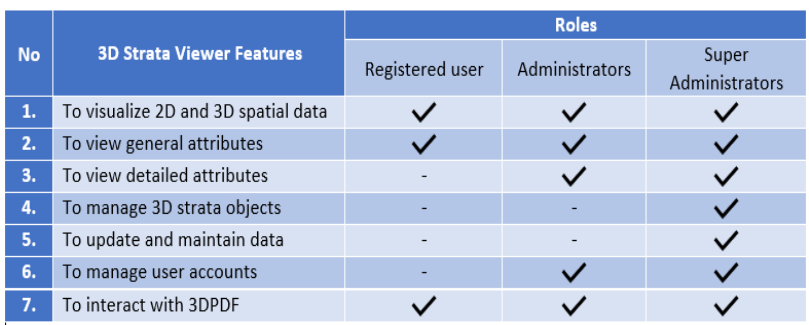

Table 2. User interactions with 3D Strata Viewer

From the features listed above, one, four, and seven are related to visualization while two, three, and six are related to data management. Number five, which is to update and maintain data applied to both visualization and data management part.

\subsection{Discussions}

This study might contribute to an online web application for a $3 \mathrm{D}$ visualization that can be accessed by selected type of user. The idea is to diminish the need of using commercial software that requires installation and payment. The visualization should be ready to be integrated with various databases and can be apply to any web browser.

The application of 3D Strata Viewer is developed based on the existing, commonly used 3D web viewer that is available today. The requirement tools in developing a user interface (UI) also have been identified based on the previous studies by many researches worldwide. The conceptual model for strata objects is based on the current development of Malaysian LADM Country Profile. The process starts with the preparation of data 
consist of 3D modelling, geolocation, and data conversion before it can be visualize using a web platform (Cesium). Some of the visualization features included in the viewer is highlights, transparency (replace wireframe), and cross-section view. The prototype could be used to query, view, and interpret ownership RRRs relevant to a property in a 3D web-based environment for a selected user group classified as Registered user, Administrator, and Super Administrator. The result shown in this paper is only preliminary that represent the building mode but not at strata level. However, the visualization of data shown in Figure 7, is drawn based on measurement of strata property (unit by unit) with common property (lifts and stairs) and ready for strata visualization.



Figure 7. shows the visualization of Melana Apartment in Cesium Viewer

\section{CONCLUSION}

Third-dimensional data is widely applied in a wide variety of fields, including, smart cities, real estate, tourism, and urban planning. It is advantageous to visualize it online or web browsers to help disseminate and sharing information without the need of any additional software or plugins. An application of a '3D Strata Viewer' will allow user to retrieve, to view, to query strata information using an interactive viewpoint. Based on the considered requirement, Cesium has the ability to view each object along with its attribute as a 3D browser which is crucial for the strata application. However, this paper only focusing on finding solution of the linking between the 3D object and its legal information by using a standardized LADM data model for strata objects (Malaysian Country Profile). The proposed prototype will be a good starting point for development of a modern strata application that allows visualization of $3 \mathrm{D}$ properties, intuitive interfaces, database solutions, and 3D spatial data visualization techniques to be built.

\section{ACKNOWLEDGEMENTS}

The author express gratitude to Dr Muhammad Imzan Hassan and Prof. Alias Abdul Rahman on the help of monitoring and supervising the research work. Authors also acknowledged the support of 3D GIS Research lab members in the preparation and development of the research. This research is funded by UTM Research University Grant, (Vot Number: Q.J130000.3552.05G54).

\section{REFERENCES}

Aditya, T., Laksono, D., Susanta, F. F., Istarno, I., Diyono, D., \& Ariyanto, D. (2020). Visualization of 3D Survey Data for
Strata Titles. ISPRS International Journal of Geo-Information, 9(5), 310.

Adobe Acrobat (2020). Displaying 3D models in PDFs, Adobe Acrobat. Retrieved from https://helpx.adobe.com/acrobat/using/displaying-3d-modelspdfs.html

Aien, A., Kalantari, M., Rajabifard, A., Williamson, I., \& Shojaei, D. (2012). Developing and testing a 3D cadastral data model a case study in Australia.

Biljecki, F., \& Sindram, M. (2017). Estimating building age with 3D GIS. Paper presented at the Proceedings of the 12th International 3D GeoInfo Conference 2017.

Bhatt, R. K. (2020). A beginner's guide for strata property owners in Malaysia. Retrieved from https://www.iproperty.com.my/guides/beginners-guide-forstrata-property-owners-in-malaysia-faq/

Cemellini, B., Thompson, R., Van Oosterom, P., \& De Vries, M. (2018). Usability testing of a web-based 3D Cadastral visualization system. Paper presented at the Proceedings of the 6th International FIG Workshop on 3D Cadastres, Delft, The Netherlands.

Chong, S. C. (2006). Towards a 3d Cadastre in Malaysia: An implementation evaluation.

Hashim, M. N., Hassan, M. I., \& Rahman, A. A. (2018). 3D Modelling towards Strata Registration. International Archives of the Photogrammetry, Remote Sensing and Spatial Information Sciences, 42(4/W9).

ISO. ISO 19152:2012, Geographic Information-Land Administration Domain Model (LADM); International Organisation for Standardisation: Geneva, Switzerland, 2012. Available online: https://www.iso.org/standard/51206.html

Kalogianni, E., van Oosterom, P., Dimopoulou, E., \& Lemmen, C. (2020). 3D land administration: A review and a future vision in the context of the spatial development lifecycle. ISPRS international journal of geo-information, 9(2), 107.

Mattsson, H., \& Mansberger, R. (2017). Land governance/management systems. Land ownership and land use development. Zürich, Switzerland: vdf Hochschulverlag, 13-24.

Mete, M. O., Guler, D., \& Yomralioglu, T. J. S. Ü. M., Bilim Ve Teknoloji Dergisi. (2018). Development of 3D web GIS application with open-source library. 6, 818-824.

Oberwinter, L., \& Kovacic, I. (2012). Building Information Model Visualization Through Javascript-Enhanced 3D-PDF Interfaces.

Olfat, H., Atazadeh, B., Rajabifard, A., Mesbah, A., Badiee, F., Chen, Y., Briffa, M., Shojaei, D. (2020). Moving Towards a Single Smart Cadastral Platform in Victoria, Australia. 9(5), 303 .

PDF3D. (2018). FAQ: What is 3D PDF |. Retrieved from https://www.pdf3d.com/faq/what-is-3d-pdf-2/

PDF3D. (2020). Handling Geospatial Coordinates for 3D PDF Files. Retrieved from https://www.pdf3d.com/handlinggeospatial-coordinates/ 
Pouliot, J., \& Wang, C. (2014). Visualization, Distribution and Delivery of 3D Parcels: Position Paper 4.

Pouliot, J., Ellul, C., Hubert, F., Wang, C., Rajabifard, A., Kalantari, M., ... \& Ying, S. (2018). 3D Cadastres Best Practices, Chapter 5: Visualization and New Opportunities. In 26th FIG Congress 2018" Embracing our Smart World Where the Continents Connect: Enhancing the Geospatial Maturity of Societies. International Federation of Surveyors (FIG).

PROSTEP.US. 3D PDF Technology for CAD Collaboration · PROSTEP.US. Retrieved from https://prostep.us/home/solutions/3d-pdf-technology

Rajabifard, A., Atazadeh, B., Kalantari, M., Olfat, H., Shojaei, D., \& Badiee, F. (2021). Design and development of an LADMdriven 3D Land administration system: Lessons learned in Malaysia. Land use policy, 102, 105252.

Rees, E. V. (2019). Visualizing 3D spatial data in a web browser using Cesium, FME and 3D tiles.

Shojaei, D. (2012). 3D visualisation as a tool to facilitate managing land and properties. In A. Rajabifard \& M. Kalantari (Ed.), A national infrastructure for managing land information: research snapshot (pp. 88-94). Centre for Spatial Infrastructures, Land Administration, Department of Infrastructure Engineering, University of Melbourne.

Shojaei, D., Olfat, H., Rajabifard, A., Kalantari, M., \& Briffa, M. (2018). Moving towards a fully operational 3D digital cadastre: Victoria, Australia. Paper presented at the Proceedings of the 6th International FIG 3D Cadastre Workshop, Delft, The Netherlands.

Vandysheva, N., Sapelnikov, S., Van Oosterom, P., De Vries, M., Spiering, B., Wouters, R., . . Penkov, V. (2012). The 3D cadastre prototype and pilot in the Russian Federation. Proceedings FIG Working Week 2012, Territory, environment and cultural heritage, Rome, Italy, May 6-10, 2012. 


\section{APPENDIX}



Appendix A: The spatial component of strata objects model 




Appendix B: The non-spatial component of strata objects model 